\title{
KARIN AĞRISININ NADİR BİR NEDENİ: APENDIKS MUKOSEL OLGU SUNUMU
}

\section{A Rare Cause of Abdominal Pain: A Case of Appendiceal Mucocele}

\section{Faruk PEHLIVANLI ${ }^{1}$, Gökhan KARACA ${ }^{1}$, Çağatay Erden DAPHAN ${ }^{1}$, Oğuz EROĞLU², Sevilay VURAL ${ }^{3}$, Figen COŞKUN ${ }^{2}$}

\author{
${ }^{1}$ Kırlkkale Üniversitesi Tıp Fakültesi Genel Cerrahi Anabilim Dall, KIRIKKALE, TÜRKIYYE \\ ${ }^{2}$ Kırıkkale Üniversitesi Tıp Fakültesi Acil Tıp Anabilim Dalı, KIRIKKALE, TÜRKIYYE \\ ${ }^{3}$ Yozgat Bozok Üniversitesi Tıp Fakültesi Acil Tıp Anabilim Dall, YOZGAT, TÜRKIYYE
}

\section{ÖZ}

\section{ABSTRACT}

Apendiksin mukoseli, apendiks lümeninin anormal müsinöz sekresyonu sebebiyle dilatasyonu ile karakterize nadir görülen klinik bir durumdur. İnflamatuar bir duruma veya tümör kaynaklı olabilir. Mukosel, mukozal hiperplazi, müsinöz kistadenom veya müsinöz kistadenokarsinom sonucunda oluşabilir. Apendiks müsinöz kistadenomu en s1k görülen şekli olup çok farklı klinik durumlarla kendini belli eder. Apendektomi spesimenlerinin \%0.2-0.3'ünde saptanır. Preoperatif tanı konması zordur ve s1klıkla laparotomide saptanır. Rüptür riski, klinik olarak cerrahları zorlamaktadır. Cerrahi planlanmasında tam bir konsensus olmamakla birlikte genellikle apendektomi ya da sağ hemikolektomi ameliyatları uygulanır. $\mathrm{Bu}$ yazımızda plastron apendisit tanısıyla takip edilip sağ alt kadran ağrısı ve kitle saptanan apendiks mukosel olgusunu literatür eşliğinde tartıştık.

Anahtar Kelimeler: Mukosel, apendiks, kistadenom, apendektomi
Appendiceal mucocele is a rare clinical condition characterized by dilatation of the appendix lumen due to abnormal mucin secretion. It may be due to inflammatory conditions or neoplastic lesions. Mucocele may occur as a result of mucosal hyperplasia, mucinous cystadenoma or mucinous cystadenocarcinoma histopathologically. Mucinous cystadenoma is the most common form and it manifests itself as many different clinical pictures. It is detected in $0.2-0.3 \%$ of appendectomy specimens. As preoperative diagnosis is often difficult, it is generally detected during laparotomy. Appendiceal mucocele is a clinical challenge for surgeons due to its risks of perforation and dissemination. Although there is no consensus for type of surgical treatment, appendectomy or right hemicolectomy are usually prefered. Herein, we present an appendiceal mucocele cystadenoma case with right lower quadrant pain and palpable mass who was followed up with the pre-diagnosis of plastron appendicitis in the context of the literature.

Keywords: Mucocele, appendix, cystadenoma, appendectomy 


\section{GİRIŞ}

Apendiks vermiformis tümörlerinin büyük bir kısmı akut karın kliniği ile acil cerrahi girişim gerçekleştirilen hastalıkların başında gelen akut apandisit nedeniyle ya da başka bir sebeple yapılan laparotomilerde tespit edilmektedir $(1,2)$. Bu tümörler gelişmiş görüntüleme yöntemlerine rağmen operasyondan önce nadiren tanı alabilirler (1). Apendiks mukoselleri, anormal müsinöz sekresyonlara bağlı olarak apendiks lümeninin dilatasyonuyla ortaya çıkan kitlelerdir. Anormal müsin birikimi retansiyon, mukozal hiperplazi, kistadenom ya da kist adenokarsinoma bağlı olabilir. Genellikle 50 yaş üstünde görülmekte ve kadınlarda daha fazla saptanmaktadır $(1,3)$. Oldukça nadir görülen bir klinik durum olup, apendektomi materyallerinin \%0.2-0.3'ünde rapor edilmiştir (4). Bu olguda plastrone apandisit nedeniyle dış merkezde takip önerilip ani başlayan sağ alt kadran ağrı ve kitleyle gelen bir mukosel olgusu sunulmaktadır.

\section{OLGU}

38 yaşında erkek hasta aralıklı sağ alt kadranda ağrı ve dispeptik şikâyetleri nedeniyle, dış merkezde iç hastalıkları polikliniğine başvurmuş, yapılan fizik inceleme ve tetkikleri sonucunda plastrone apendisit ile uyumlu görünüm tespit edilmesi üzerine kontrol önerilen hasta, sağ alt kadranda ağrı şikayetlerini artması üzerine hastanemiz acil servisine başvurmuştur. Hastanın yapılan değerlendirmesinde defans, rebaund ve hassasiyet mevcuttu. Kan

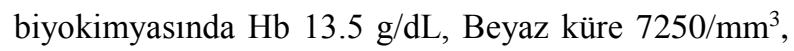
CRP 40 mg/L, AST 12 U/L, ALT 13 U/L, ALP 82, GGT 70 U/L saptandı. Karın ultrasonografisinde sağ alt kadranda $20 \mathrm{~mm}$ bağırsak ansını çevreleyen $85 \times 65$ mm boyutunda yoğun içerikli sıv1 koleksiyonu, apendiks mukoseli ile uyumlu görünüm tespit edildi. Karın bilgisayarlı tomografisinde (BT) sağ alt kadranda çekumu, çıkan kolonun proksimal kesimini ve ileal ansları komprese eden çekumla yakın ilişkili, duvarında ve içerisinde kalsifikasyonlar bulunan yaklaşık 12x9 cm boyutlarında ince cidarlı kistik kitle olarak raporland1 (Resim 1-2).

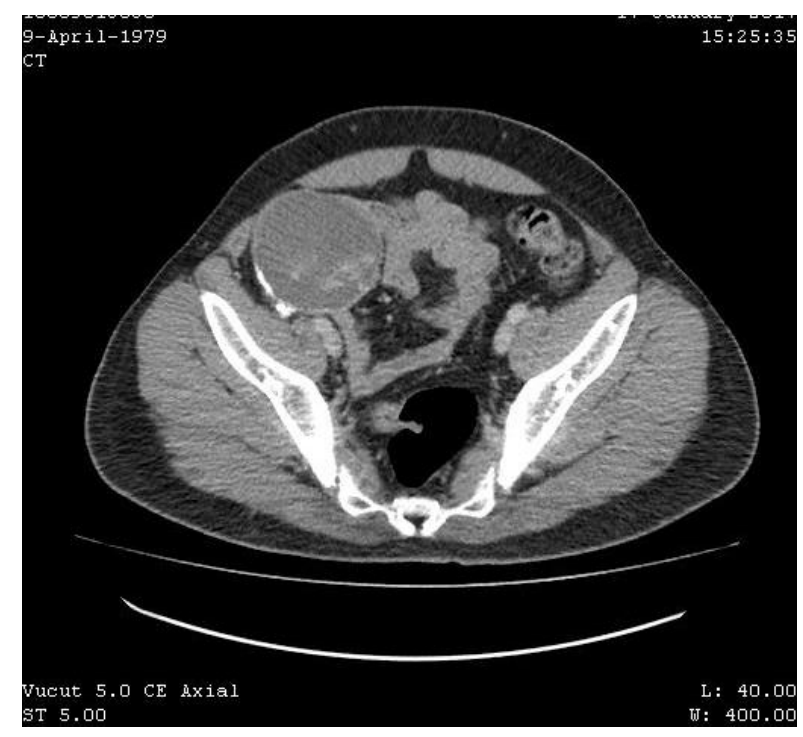

Resim 1: Sağ alt kadranda çekumu, çıkan kolonun proksimal kesimini ve ileal ansları komprese eden çekumla yakın ilişkili, duvarında ve içerisinde kalsifikasyonlar bulunan kitlenin karın bilgisayarlı tomografisinde aksial görüntüsü izlenmektedir.

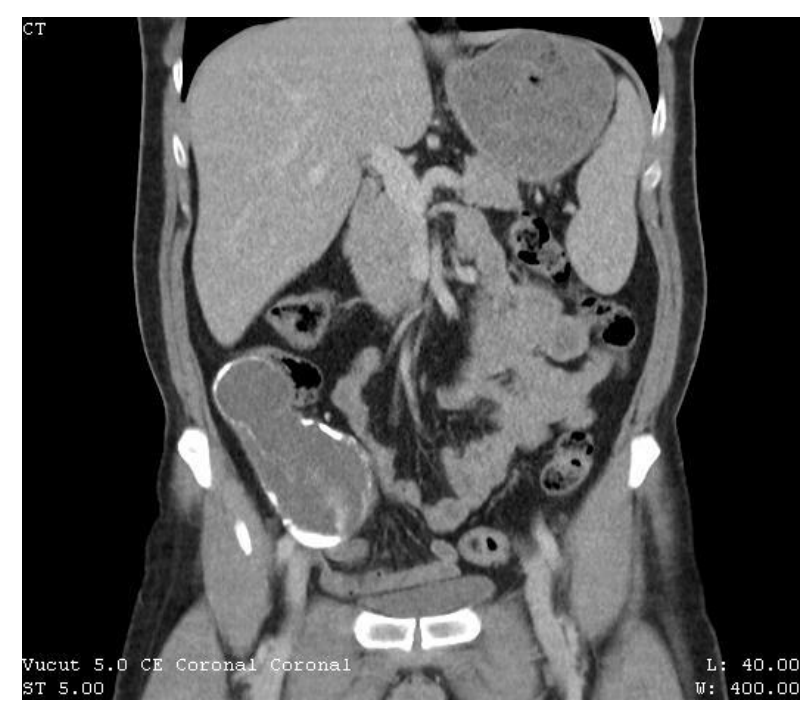

Resim 2: Karın bilgisayarlı tomografisinde sağ alt kadranda çekumu, çıkan kolonun proksimal kesimini ve ileal ansları komprese eden çekumla yakın ilişkili, duvarında ve içerisinde kalsifikasyonlar bulunan kistik kitlenin koronal görüntüsü. 
Sağ alt kadranda aralıklı ağrı şikayetleri olan hastaya tanısal laparotomi planlandı. Laparotomide ileoçekal bölgede belirgin dilatasyon ve omentumla sarıl1 plastrone görünümde apendiks mukoseli_izlendi (Resim 3). Kitle çekum tabanından ayrilarak total rezeke edildi. Hasta postoperatif ikinci günde oral alım açıldıktan sonra altıncı günde taburcu edildi.
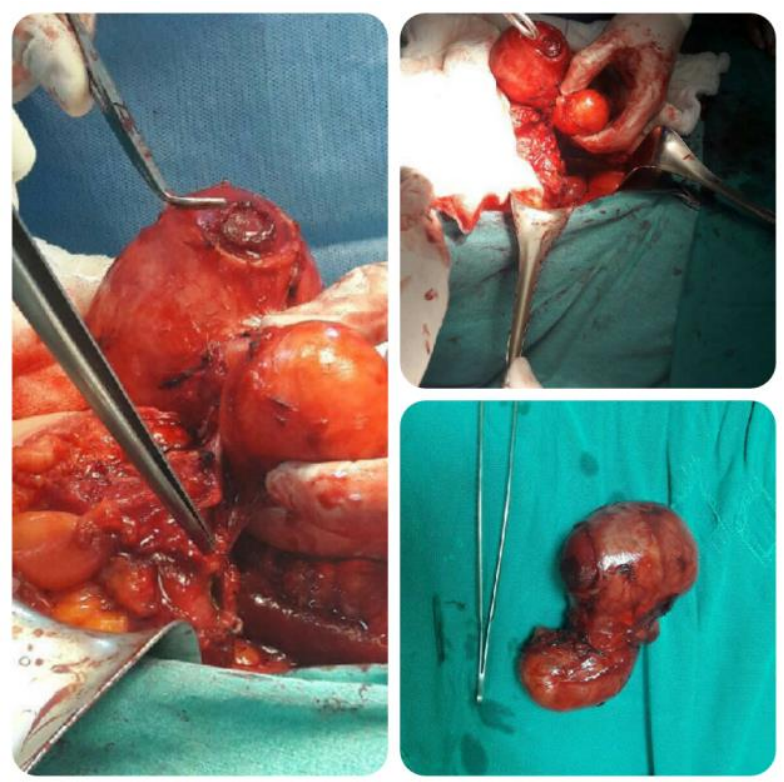

Resim 3: Laparotomide ileoçekal bölgede belirgin dilatasyon ve omentumla sarılı plastrone görünümde apendiks mukoseli.

\section{TARTIŞMA}

Apendiks mukoseli patolojik olarak ilk defa 1842 yılında Rokitansky tarafindan tanımlanmış, isimlendirme ise 1876 yllinda Feren tarafindan yapılmışır (5). Apendiks mukoseli sağ alt kadran hassasiyeti bulgusu verebilir; fakat genellikle asemptomatiktir ve intraoperatif olarak tanı konulur (68). Literatürde operasyondan önce tanısı konmuş az sayıda vaka bildirilmiş̧tir (9). Klasik olarak şüpheli apandisit vakalarının laparotomileri sırasında tanı konur. Apendiks mukoselinin tipik radyolojik bulgusu, apendiks bölgesinde kistik kitle varlığıdır. BT tanıda önemlidir. Düz karın grafisinde sağ alt kadranda kalsifikasyon içeren ya da içermeyen yumuşak doku kitlesi şeklinde görülebilir (10). Kitlenin sebebi müsine bağlı genişleme olabileceği gibi olgumuzdaki gibi müsine bağlı inflamasyon nedeniyle plastrone apandisit görünümü de olabilir. Olgumuzda inflamasyon; başka bir merkezde verilen medikal tedavi ile gerilemiş ve hasta ileri bir zamanda elektif apendektomi uygulanmak üzere taburcu edilmiştir.

Ayırıcı tanıda, apendiks neoplazileri de düşünülebilir. Apendiks neoplazileri klasik olarak apandisit bulguları vermemesine rağmen, apendiksin obstrüksiyonuna bağlı lümen tıkanıklığı sonucu enfeksiyon geliştiğinde hastada akut apandisit kliniği görülebilir (11). En sık rastlanan apendiks neoplazmaları karsinoidlerdir; apendiks adenokarsinomlarına ise \%1.4 oranında rastlanır $(1,3)$. Bazı histopatolojik çalışmalar apendiks mukozasından gelişen neoplastik değişikliklerin mukosele yol açtı̆̆ını göstermiştir. Bu lezyonlar histopatolojik olarak; retansiyon kistleri, mukozal hiperplazi, benign kistadenom (bening mukosel) ve kistadenokarsinom olmak üzere dört kategoride incelenir (12).

Mukozal epiteliyal hiperplazide, kolumnar hücreler çok fazla miktarda müsin üretirler; ancak apendikste rüptür veya peritoneal mukozal implant meydana gelmez. Kistadenomlarda kistin içini döşeyen kolumnar epitelin papiller projeksiyonları mevcuttur. Kistadenomlarda $\% 20$ olguda lümen dilatasyonu ve apendiks perforasyonu görülür. Lümen perforasyonu; apendiks serozasının tutulumu, lokalize mukus koleksiyonlarına veya peritoneal boşlukta herhangi bir yere implante olan mukus koleksiyonlarına neden olabilir. Mukusun histolojik incelenmesinde neoplastik hücrelere rastlanmaz ve apendektomi küratif tedavi yöntemidir $(1,13)$. Bizim olgumuzda da apendiks lümen perforasyonu mevcuttu ve ayrıca patolojik olarak da kistektomi materyalinde malign hücreye rastlanmadı.

Apendiksin müsinöz neoplazilerinin tanısının preoperatif olarak konması, seçilecek cerrahi teknik (laparoskopik/açık) ve uygulanacak cerrahi işlem (sağ hemikolektomi/apendektomi) açısından önemlidir (9). Mukosel ameliyatlarından sonra görülen en önemli 
komplikasyonlardan biri pseudomiksoma peritonei olduğundan; operasyon sırasında kist rüptürü ve kist sıvısının sızmamasına özen göstermek ve özellikle rüptüre sebep olacak manipulasyonlardan kaçınmak gerekir. Altta yatan nedenin müsinöz kist adenokarsinom olduğu durumlara bağlı gelişen psödomiksoma peritonei'de beş yıllık sağ kalım oranı \%20'lere kadar düşmektedir (14). Çekum invazyonu ve çevre organ tutulumunda sağ hemikolektomi endikasyonu mevcuttur. Olgumuzda operasyon esnasında lümeni tıkayan patolojinin fekalite bağlı olmadığı, genişlemenin tümöre bağlı olabileceği düşünülmesine rağmen, kesin patolojisi bilinmediğinden ve çevre dokuya invazyon gözlenmediğinden, gereğinde patoloji sonucuna göre başka bir operasyon planlanabileceği düşünülerek apendektomi yapılıp operasyona son verilmiştir.

Sonuç olarak apendiksin mukoseli nadir görülmekte ve plastrone apandisiti taklit edebilmektedir. Tanı ultrasonografi veya BT ile preoperatif ya da çıkarılan dokunun histopatolojik incelemesi ile konabilmektedir. Ultrasonografide kitle görüntüsü veren tüm olgularda apendiksin neoplastik lezyonları akılda tutulmalıdır.

\section{KAYNAKLAR}

1. Aho AJ, Heinonen R, Lauren P. Benign and malignant mucocele of the appendix. Histological types and prognosis. Acta Chir Scand. 1973;139(4):392-400.

2. Aydin O, Aydin G, Pircaoğlu E, Civelek S, Pehlivanlı F, Karaca G. A Rare appendiceal anomaly: agenesis of the vermiform appendix. KÜ T1p Fak Derg. 2017;19(1):37-40

3. Dhage-Ivatury S, Sugarbaker PH. Update on the surgical approach to mucocele of the appendix. J Am Coll Surg. 2006;202(4):680-4.

4. Aydin O, Pehlivanli F, Karaca G, Aydin G, Özler I, Daphan ÇE. Mucinous cystadenoma of the appendix. Apollo Med. 2018;15:116-7.
5. Takahashi S, Furukawa T, Ueda J. Case report: Mucocele of the tip of the appendix. Clin Radiol. 1998;53(2):149-50.

6. Roberge RJ, Park AJ: Mucocele of Appendix. J Emerg Med. 2006;30(3):303-6.

7. Korkolis DP, Apostolaki K, Platoniotis GD, Tzorbatzoglou J, Karaitianos IG, Vassilopoulos PP. Mucocele of appendiceal stump due to benign mucinous cystadenoma, Anticancer Res. 2006;26(1B):635-8.

8. Soweid AM, Clarkston WK, Andros $\mathrm{CH}$, Janney CG. Diagnosis and management of appendiceal mucoceles. Dig Dis. 1998;16(3):183-6.

9. Kılıç K, Araç M, Özer S, Özakpınar E. Appendiksin musinoz kistadenomu. Tanısal ve Girişimsel Radyoloji. 2001;7(1):128-30.

10. Kim SH, Lim HK, Lee WJ, Lim JH, Byun JY. Mucocele of theappendix: ultrasonographic and CT findings. Abdom Imaging. 1998;23(3):292-6.

11. Bittle MM, Chew FS. Radiological reasoning: recurrent right lower quadrant inflammatory mass. Am J Roentgenol. 2005;185(3):188-94.

12. Brunicardi FC, Andersen DK, Billiar TR. Schwartz's Principles of Surgery. 8th ed, NewYork. McGraw-Hill, 2005.

13. Cotran RS, Kumar V, Robbins SL. Pathologic Basis of Disease. 5th ed, Philadelphia. W.B. Saunders Company, 1994.

14. Rosai J. Mucinous tumor like conditions (Including so-called "mucocele"). In: Rosai J, ed. Rosai and Ackerman's Surgical Pathology. 9th ed, Philadelphia. Elsevier Mosby, 2004:761-5. 